\title{
Problemas ambientais desencadeados pelo Plano Nacional de Agroenergia: o caso de Itapuranga, Goiás
}

Environmental problems caused by the Brazilian Agroenergy Plan: the case of Itapuranga, Goiás

Problemas ambientales provocados por el Plan Nacional de Agroenergía: el caso de Itapuranga, Goiás

Les problèmes environnementaux causés par el Plan Agroénergétique Brésilien: le cas de Itapuranga, Goiás

\author{
Simone Pereira de Carvalho* \\ Joel Orlando Bevilaqua Marin**
}

Recebido em 2/9/2010; revisado e aprovado em 30/11/2010; aceito em 12/12/2010

\begin{abstract}
Resumo: O artigo analisa as contradições entre os discursos oficias que legitimam a política nacional agroenergética e os problemas ambientais desencadeados pela expansão da monocultura canavieira em territórios de agricultura familiar. O estudo de caso foi realizado no município goiano de Itapuranga, combinando pesquisa documental, bibliográfica e entrevistas. Conclui-se que a política agroenergética agravou os problemas ambientais em Itapuranga e provocou alterações nas relações sociedade e natureza.
\end{abstract}

Palavras-chave: Políticas agroenergéticas. Agricultura familiar. Meio ambiente.

Abstract: This article analyzes the contradictions between the official discourses, wich legitimize the Brazilian Agroenergy Plan, and environmental problems caused by the expansion of sugarcane monoculture in family farming areas. The case study was conducted in Itapuranga, state of Goiás, combining desk research, literature review and interviews. The main conclusion is that the agro-energy policy has increased environmental problems in Itapuranga and has changed the relation between society and nature.

Key words: Agro-energy policy. Family farm. Environment.

Résumé: L'article examine les contradictions entre les discours officiels qui légitiment la politique brésilienne de agroénergie et problèmes environnementaux causés par l'expansion de la monoculture de canne à sucre dans les domaines de l'agriculture familiale. L'étude de cas a été réalisée en Itapuranga, municipalité de l'État de Goiás, avec la association de la recherche documentale, la recherche biliographique et entrevues. Nous concluons que la politique de l'agroénergie aggravé les problèmes de l'environnement dans Itapuranga et provoqué changements dans las relations société et nature.

Mots-clés: Politique agro-énergie. Agriculture familial. Environnement.

Resumen: El artículo realiza un análisis de las contradicciones entre los discursos oficiales que legitiman la Política Nacional de Agroenergía y los problemas ambientales ocasionados por la expansión del monocultivo de la caña de azúcar en áreas de la agricultura familiar. El estudio de caso fue realizado en Itapuranga, municipio de la Provincia de Goiás, combinando investigación documental, bibliográfica y entrevistas. Se llegó a la conclusión de que la política agroenergética incrementó los problemas ambientales en Itapuranga y trajo alteraciones en las relaciones sociedad y naturaleza.

Palabras clave: Políticas agroenergéticas. Agricultura familiar. Medio ambiente.

\section{Introdução}

A emergência de problemas relacionados ao abastecimento de petróleo obrigou o Estado brasileiro a retomar as políticas agroenergéticas para produção de biocombustíveis, materializadas no Plano Nacional de Agroenergia (2006-2011). A produção de álcool com a matéria-prima cana-de-açúcar aparece como a alternativa viável, visto que o país acumulou certo domínio tecnológico para sua produção. Com isso, espera-se uma nova expansão do setor canavieiro marcada por uma redistribuição espacial da produção com tendências de aumento nos Estados de Minas Gerais, Mato Grosso do Sul, Mato Grosso e Goiás.

O Estado de Goiás demonstra certos atrativos à instalação de agroindústrias

\footnotetext{
* Mestre em Agronegócio pela Universidade Federal de Goiás. E-mail: siimoni@gmail.com. Este artigo é parte da dissertação de mestrado intitulada Agricultura familiar e agroindústria canavieira: integrações e contradições, defendida por Simone Pereira de Carvalho, sob a orientação do professor Joel Orlando Bevilaqua Marin. A dissertação contou com apoio financeiro do CNPq e recebeu o PRÊMIO SOBER (Sociedade Brasileira de Economia, Administração e Sociologia Rural), de melhor dissertação de mestrado em Sociologia Rural no ano de 2009.

** Doutor em Sociologia, professor da Universidade Federal de Santa Maria. E-mail: bevilaquamarin@gmail.com.
} 
canavieiras, tais como: preço competitivo das terras, clima satisfatório, incentivos fiscais e, principalmente, localização geográfica favorável ao escoamento da produção. Em 2007, das agroindústrias, 25 estavam em operação e 52 em fase de implantação, análise ou cadastramento, com a possibilidade de Goiás tornar-se o segundo produtor nacional de álcool. O governo prevê que a expansão da cultura da cana-de-açúcar no Estado se dará em áreas de pastagens. No entanto, há evidências de que a monocultura da cana-de-açúcar também adentrou áreas de predominância da agricultura familiar, a exemplo do município goiano de Itapuranga, desencadeando rápidas transformações ambientais.

Os pontos de legitimação social do novo programa agroenergético baseiam-se em supostos benefícios ambientais decorrentes da utilização dos biocombustíveis, por remeter à construção do propalado desenvolvimento sustentável. Ao atrelar a política agroenergética aos pressupostos do desenvolvimento sustentável, o Estado demonstra que partilha dos ideais defendidos pela sociedade e trabalha no intuito de atender aos anseios dos cidadãos. No entanto, em determinados contextos, a noção de desenvolvimento sustentável é utilizada como uma ideologia, para ressaltar as vantagens ambientais e obnubilar as contradições socioambientais associadas à expansão da monocultura canavieira.

Neste artigo apresenta-se uma análise das contradições existentes entre o discurso da questão ambiental da política agroenergética e os problemas ambientais desencadeados com a expansão da monocultura canavieira em Itapuranga. Segundo Bourdieu (1997), não há como estabelecer a lógica do mundo social sem ser por meio do estudo particular de uma realidade empírica, historicamente situada e datada. Assim, o estudo de caso realizado em Itapuranga oferece elementos para a compreensão das contradições ambientais que emergem da expansão da cultura canavieira, desencadeada no âmbito da política agroenergética brasileira.

O problema recebeu uma abordagem qualitativa, sendo que os dados foram levantados com a combinação da pesquisa bibliográfica e documental e, especialmente, entrevistas. Entrevistaram-se quinze famílias de agricultores familiares de Itapuranga.
Desse total, onze estabeleceram contratos de integração com a agroindústria canavieira. Também foram entrevistados agentes sociais de representação de algumas instituições de Itapuranga, tais como: sindicato dos empregadores rurais, sindicato dos trabalhadores rurais, Igreja católica, Secretaria da Agricultura e do Meio Ambiente do Município, Organização dos Amigos de Itapuranga (OAI), AgenciaRural, Câmara dos Dirigentes Lojistas e Cooperativa de Agricultura Familiar de Itapuranga (COOPERAFI). Analisaram-se os problemas ambientais de Itapuranga sob o ponto de vista dos diferentes agentes sociais, com destaque para os problemas da queima da cana, redução da biodiversidade natural e degradação do solo e dos recursos hídricos.

\section{A questão ambiental no discurso do Plano Nacional de Agroenergia}

De acordo com Bourdieu (1990), a realidade social deve ser considerada "um objeto de percepção". No exercício do poder, o Estado impõe seu ponto de vista, que se institui como a visão de mundo legítima, que todos devem reconhecer, ao menos dentro dos limites de uma determinada sociedade, por meio de seus aparatos legais, discursos, projetos, programas ou planos políticos. Dessa forma, cabe à ciência social "tomar como objeto não apenas essa realidade, mas também a percepção dessa realidade, as perspectivas, os pontos de vista que, em função da posição que ocupam no espaço social objetivo, os agentes têm sobre essa realidade" (BOURDIEU, 1990, p. 156).

O Estado explora a possibilidade de mudar o mundo social modificando a representação do mundo através de uma pré-visão, que funciona como uma "previsão" que contribui para a produção de um novo senso comum e para a construção da realidade que anuncia. Segundo Bourdieu (1998c, p. 53), “os discursos não são apenas [...] signos destinados a serem compreendidos, decifrados; são também signos de riqueza a serem avaliados, apreciados, e signos de autoridade a serem acreditados e obedecidos".

Nos discursos oficiais relacionados ao Programa Nacional de Agroenergia, os representantes legítimos do Estado apresentam sua visão de mundo como uma demanda social extraída da coletividade, como se fosse o 
próprio desejo da sociedade se transformando em realidade. Dessa forma, o então ministro da Agricultura Pecuária e Abastecimento (MAPA) se manifesta:

Conclamamos [...] a sociedade em geral a se integrarem neste esforço nacional, para transformar estas oportunidades em realizações. Juntos, vamos construir um novo paradigma de desenvolvimento, em bases sustentáveis da nossa agroenergia. (MAPA et al., 2005a, p. 3).

Bourdieu (1990) explica que, no domínio simbólico, os atos de força traduzem-se em "atos de forma". Quando um representante autorizado do Estado quer empreender um ato de força, ele passa do "eu" ao "nós". Ele não afirma: "Vou construir um novo paradigma [...]"; mas: "Juntos, vamos construir [...]"; ou ainda: "Venham todos se integrar nesse esforço nacional [...]". Nesse caso, o interesse do Estado aparece necessariamente como interesse proclamado do povo, com vistas a modificar a visão de mundo do povo.

Segundo Bourdieu (1990), a visão de mundo do Estado se exprime nos discursos oficiais, quanto este impõe seu ponto de vista legítimo, isto é, "iluminado", ao qual toda sociedade deve reconhecer. Em relação ao programa agroenergético não foi diferente. Num primeiro momento, o discurso oficial procurou fazer um diagnóstico dos problemas relacionados à questão energética, apontando que as atuais reservas de petróleo durarão apenas quarenta anos, se forem mantidos os atuais níveis de consumo, mas a previsão é que a demanda cresça mais do que a oferta, provocando elevação dos preços. Isso será agravado pelas preocupações com as mudanças climáticas globais, em virtude das expectativas de incorporação dos custos ambientais aos preços dos combustíveis fósseis. Em suma, de acordo com o ponto de vista oficial do Estado, o Brasil e o mundo encontram-se na iminência de uma crise energética e ambiental. Frequentemente, a causalidade dos problemas ambientais é atribuída à produção e consumo de combustíveis fósseis, daí que a solução passa pela busca de alternativas energias renováveis (MAPA et al., 2005a, 2005b; BRASIL, 2006).

O Estado difunde a política agroenergética como uma solução para os problemas energéticos e ambientais. No momento, essa ideia encontra na sociedade um ambiente favorável para sua aceitação e aprovação, uma vez que os biocombustíveis são apresentados como uma solução para os problemas energéticos e ambientais do mundo contemporâneo, ao passo que os combustíveis fósseis são considerados escassos e poluidores. Em torno dessas questões, o Estado tece justificativas para legitimar a promoção das políticas agroenergéticas, em substituição ao petróleo.

Bourdieu (1998a, 1998c, 1996, 1990) explica que a violência exercida pelo Estado baseia-se no poder de impor às outras mentes uma nova visão de mundo, embutido num discurso oficial. O Estado age sobre o mundo social por meio das representações que os próprios agentes sociais têm do mundo, alcançando sua legitimidade social ao mesmo tempo em que exerce seu poder sobre a sociedade. Nas lutas pela imposição de um ponto de vista legítimo, o discurso científico é comumente utilizado para fundamentar o ponto de vista do Estado.

Normalmente, o Estado elege uma equipe de estudiosos ou cientistas para produzir um novo ponto de vista ajustado à conveniência, enfocando determinados aspectos em detrimento de outros. Isso decorre do fato de a descrição científica, ao tornar pública a propensão de um determinado acontecimento se concretizar, contribuir para reforçar a "pretensão de sua existência", pois faz com que os agentes se preparem para contornar os problemas anunciados pelo discurso científico (BOURDIEU, 1996). Nesse caso em específico, o Estado se apropria do discurso científico que associa a utilização de combustíveis fósseis aos fatores responsáveis pelas alterações climáticas globais, com destaque para o aquecimento global. Este é responsável, dentre outras coisas, pela ocorrência de catástrofes como secas, cheias, furacões etc., alteração no regime de chuvas, formação de tempestades com alto poder de destruição, aumento de incêndios florestais, elevação do nível das águas oceânicas, tanto pela expansão térmica quanto pelo derretimento das geleiras, dentre outras consequências desastrosas.

Nos discursos oficiais, o Estado reconhece que a questão ambiental será um fator viabilizador da adoção da agroenergia: "a curto prazo, uma das forças propulsoras da demanda por agroenergia será a pressão ambiental pela substituição de combustíveis 
fósseis" (MAPA et al., 2005, p. 7). Soma-se ainda a preocupação ambiental para limitar as emissões de gás carbônico que, encontrado em altas concentrações na atmosfera, é considerado o principal responsável pela intensificação do efeito estufa e pelo aquecimento global. A solução apontada para a problemática remonta à substituição do petróleo pelos biocombustíveis, produto considerado menos poluente:

A crescente preocupação com as mudanças climáticas globais convergirá para políticas globais de redução da poluição e para o reconhecimento da importância da energia de biomassa. (MAPA et al., 2005b, p. 54).

Tais afirmações baseiam-se no fato de os biocombustíveis, quando utilizados em mistura ou em substituição aos combustíveis fósseis, serem capazes de reduzir ou evitar as emissões de gases poluentes na atmosfera, principalmente, de gás carbônico e de chumbo tetraetila - produto muito danoso à saúde humana.

O Estado ressalta ainda que as emissões de gás carbônico na atmosfera, decorrentes da utilização dos biocombustíveis, poderão convergir em oportunidades de negócios para o país, em decorrência do aumento da demanda assentada na necessidade de os países desenvolvidos atenderem aos acordos de redução das emissões de gás carbônico, firmados no Protocolo de Quioto. Assim, com a produção de agroenergia, o Estado pretende aproveitar as condições instauradas e lucrar com o comércio internacional de biocombustíveis para os países signatários do referido Protocolo. O país também busca se beneficiar com os investimentos do Mecanismo de Desenvolvimento Limpo (MDL) no setor florestal e energético e aumentar sua participação no mercado de créditos de carbono: "O País tem condições para se tornar o principal receptor de recursos provenientes do mercado de carbono, cujos contornos já estão visíveis e serão rapidamente adotados em razão da entrada em vigor do Protocolo de Quioto" (MAPA et al., 2005b, p. 51).

As culturas agroenergéticas também estão associadas à possibilidade de estas captarem gás carbônico e liberar oxigênio durante o processo de fotossíntese, purificando o ar atmosférico. O "sequestro" de carbono pode significar uma redução anual de aproximadamente 39 milhões de toneladas de dióxido de carbono na atmosfera. Ademais, o Estado enfatiza que a produção de agroenergia se dará por meio de processos menos degradantes ao meio ambiente, em comparação com a extração de combustíveis fósseis (MAPA et al., 2005a).

Sob esses argumentos, o Estado propugna a construção social de um modelo desenvolvimento sustentável, fundamentado na expansão dos cultivos agroenergéticos. No entanto, o Estado demonstra ter ciência das dificuldades de abrangência de sua proposta e, frequentemente, argumenta que a produção da agroenergia deve concretizar-se nos "limites ambientalmente aceitáveis" (MAPA et al., 2005b, p. 7). Esses limites não são determinados pela capacidade de suporte do meio ambiente, pois, se assim o fossem, seriam verificados previamente com base nos critérios do uso sustentável e responsável dos recursos naturais. Mas, na realidade, eles remetem à degradação ambiental tolerada pela sociedade, daí que os tais "limites ambientalmente aceitáveis" serão desencadeados pelos movimentos sociais organizados, que começarão a se mobilizar e manifestar suas insatisfações, delineando os níveis de tolerância de degradação ambiental.

Como destaca Bourdieu (1990), na luta pela produção e imposição da visão legítima do mundo social, o Estado nunca obtém um monopólio absoluto, mesmo quando se alia à autoridade da ciência. Isso porque numa sociedade sempre existem conflitos e contradições entre as diferentes esferas de poder, que impõem rupturas nas visões legítimas do Estado. Esses conflitos se manifestam quando cientistas, estudiosos, organizações, instituições, dentre outros agentes, contestam os pontos de vista utilizados pelo Estado, apresentando novas maneiras de perceber a realidade social.

\section{Contradições ambientais da produção canavieira em Itapuranga}

Itapuranga localiza-se na mesorregião Centro Goiano e microrregião de Ceres, ocupa uma área aproximada de $1.277,160 \mathrm{~km}$, é formado pelos distritos de Cibele e Diolândia, bem como pelos aglomerados rurais de Lages e São José (IBGE, 2007; SEPLAN/SEPIN, 
2007). Segundo o Censo Agropecuário de 1996, aproximadamente $91,8 \%$ dos estabelecimentos rurais de Itapuranga enquadram-se na categoria familiar, uma vez que $82,97 \%$ dos imóveis rurais possuem área inferior a 80 hectares. Esses agricultores movimentam a economia local e são responsáveis por $65,7 \%$ do valor anual bruto da produção agropecuária (VBP). As propriedades são geralmente exploradas pelos próprios proprietários e geridas por responsáveis ou familiares não remunerados.

Itapuranga apresenta bons indicadores referentes ao nível de saúde, à oferta de serviços básicos e à infraestrutura. O índice de desenvolvimento humano (IDH) do município é classificado como médio, porém apresenta um baixo grau de escolaridade dos trabalhadores formais, um baixo PIB per capita e uma baixa arrecadação de impostos (SEPLAN/SEPIN, $2007,2008)$. Em função disso, o poder político local empenhou-se pelo crescimento da produção de álcool na expectativa de aumentar a arrecadação de impostos do município.

No contexto da segunda fase do PROALCOOL, foi instalada no município a agroindústria PITE S.A., mas foi desativa ainda na década de 1980. Somente em 2005, um tradicionalmente grupo de empreendimentos nordestino, que atua no complexo agroindustrial canavieiro, alugou as instalações da PITE S.A. e retomou suas atividades produtivas regulares. A reintrodução da cana em Itapuranga desencadeou diversos problemas ambientais que se tornaram questões de debate público. No estudo de caso do município de Itapuranga, as principais questões problematizadas pelos diferentes agentes sociais referem-se à queima da cana, à perda da diversidade natural e à degradação do solo e dos recursos hídricos.

Os inconvenientes advindos da queima da cana estão entre as principais reclamações dos entrevistados de Itapuranga. Rodrigues e Ortiz (2006) alertam que as queimadas emitem eteno na atmosfera, além de outros hidrocarbonetos que são precursores da formação do ozônio troposférico, o qual é responsável por problemas respiratórios em seres humanos. As queimadas também emitem diversos compostos que, uma vez depositados na água e no solo, convertem-se em ácidos, aumentando a acidez do meio. A acidificação apresenta como consequências o declínio florestal, a mortandade de peixes, a corrosão de metais e a desintegração de revestimento de superfícies metálicas e de materiais minerais de construção, dentre outras.

Segundo Ferraz (2000), a queima dos canaviais elimina grandes quantidades de fuligem e gases que agravam o efeito estufa. Os valores médios de emissão de gases, durante a queima da cana-de-açúcar no Brasil, no período de 1986 a 1996, corresponderam a $0,26 \%$ de CO2 (cerca de 64,8 milhões de toneladas/ano), $0,22 \%$ de metano $(\mathrm{CH} 4)$ e 0,7-1,0\% de óxido nítrico (N2O). Do ponto de vista ecológico, esses problemas acabam anulados ao longo do tempo, pelo próprio crescimento dos canaviais que, pelo fenômeno da fotossíntese, consome gás carbônico e libera oxigênio. Porém, isso não ocorre com todos os gases como o ozônio, os gases de nitrogênio e de enxofre.

Pasqualeto e Zito (2000) explicam que a queima dos canaviais reduz a matéria orgânica e a fauna e flora associadas ao agroecossistema. Ademais, provoca a diminuição da umidade e porosidade do solo, o que implica a alteração da concentração de gases e diminui sua fertilidade, em decorrência da exposição do terreno aos efeitos erosivos e da perda de nutrientes voláteis durante a combustão. Esses nutrientes retornam ao solo, mas na forma de chuva ácida, que é altamente nociva aos vegetais.

Mesmo que os estudos científicos coloquem em evidência esses problemas ambientais, as opiniões dos entrevistados em Itapuranga divergem acerca da eliminação das queimadas por meio da mecanização da colheita. Alguns manifestam o desejo de eliminação das queimadas e lamentam que a introdução da colheitadeira mecânica ainda não tenha acontecido. Já outros nem tanto.

Em 2002, o Estado de São Paulo, maior produtor nacional de cana-de-açúcar, promulgou a Lei n. 11.241, que proíbe a queima da cana. A referida lei prevê que, até 2020, $100 \%$ da cana colhida deixe de ser queimada em áreas mecanizáveis, ou seja, em terrenos com declividade máxima de $12 \%$. Nas áreas não mecanizáveis, o prazo para extinção das queimadas foi estendido até 2031, o que exigirá soluções tecnológicas para o setor (BIERHALS, 2007). Seguindo os moldes de 
São Paulo, em 2006, Goiás instituiu a Lei n. 15.834, que determina a redução gradativa do fogo em áreas mecanizáveis - áreas superiores a 150 hectares em terrenos contíguos com declividade inferior a $12 \%$-, obedecendo aos seguintes percentuais e prazos: em 10\% da área até 2012, em 25\% da área até 2017, em $50 \%$ até 2022 , em $75 \%$ até 2027 , sendo o ano de 2028 a data limite para extinção das queimadas. Contudo, as áreas não mecanizáveis não estão sujeitas à redução gradativa do emprego do fogo.

Até o momento há polêmicas em relação a essa determinação legal, posto que no Tribunal de Justiça do Estado (TJ-GO) tramita uma ação direta de inconstitucionalidade (ADIN) da referida Lei. A ADIN contesta a manutenção das queimadas em áreas inferiores a 150 hectares e a autorização do uso do fogo controlado em áreas mecanizáveis até o ano de 2028. Esse prazo é superior ao previsto no Código Florestal Brasileiro, regulamentado pelo Decreto Federal n. 2.661/98, que prevê a erradicação da queima da cana até 2018. A legislação goiana não pode regulamentar normas estaduais menos restritivas que as federais, daí por que a ADIN enfatiza ainda que a Lei n. 15.834 violou os preceitos contidos nos artigos 6º inciso V, e 127 da Constituição de Goiás, que asseguram a todos o direito ao meio ambiente ecologicamente equilibrado, bem como impõem ao poder público o dever de recuperá-lo e preservá-lo. Ao autorizar as queimadas, a Lei estadual goiana afronta o dever de proteção ambiental, já que a queima da cana é considerada poluidora (MINISTÉRIO PÚBLICO DO ESTADO DE GOIÁS, 2008).

No entanto, a geração de empregos configura entre os principais argumentos de legitimação do atual programa agroenergético do Estado e do afrouxamento das leis que disciplinam a queima da cana em Goiás. Dessa forma, os benefícios ambientais obtidos com a extinção das queimadas contrapõem-se ao problema social agravado pelo desemprego. A introdução de inovações tecnológicas - em particular da colheita mecanizada - nem sempre acaba com as condições insalubres e penosas a que são submetidos os trabalhadores da cana. Como observam Rodrigues e Ortiz (2006), com a expansão da mecanização da colheita da cana, os trabalhadores que experimentavam condições precárias de trabalho passam a se preocupar com o desemprego, sendo que a ameaça de desemprego conduz à aceitação de condições precárias de trabalho.

Diversos agentes sociais de Itapuranga, como os agricultores integrados à agroindústria, os trabalhadores, os comerciantes, os representantes políticos, dentre outros, tendem a aceitar os inconvenientes provocados pelas queimadas em troca da manutenção dos postos de trabalhos. O desemprego está impondo uma espécie de dominação a essas pessoas que preferem as queimadas ao desemprego. Portanto, defendem a manutenção das queimadas para evitar a redução dos postos de trabalho, em contraposição à introdução da colhedora mecânica.

Os entrevistados, em coro, afirmam que a implantação da agroindústria canavieira em Itapuranga se justifica pela possibilidade de gerar empregos, tão importantes para atender às necessidades básicas de muitos trabalhadores. Esse argumento tem certa procedência, pois somente quando as necessidades essenciais estão asseguradas é que os agentes sociais começam a se preocupar com fatores relacionados à qualidade de vida e ao meio ambiente. Via de regra os problemas ambientais advindos da implantação da agroindústria no município são percebidos como inevitáveis inconvenientes do "progresso". A introdução da colheita mecânica resolveria esse problema, mas implicaria a redução na contratação de trabalhadores braçais. Sob tais condições, o emprego torna-se algo desejável a qualquer custo.

No início das atividades do corte de cana, a empresa tentou efetuar o corte manual da cana "crua" - sem queimar -, numa área na beira do asfalto, com a intenção de evitar que o fogo se alastrasse para um posto de gasolina próximo. Apesar de o rendimento do trabalho ser menor, receberiam o equivalente ao corte da cana queimada, pois a agroindústria se comprometia a pagar a diferença da produtividade. Porém os trabalhadores não aceitaram cortar a cana crua, revoltaram-se e atearam fogo no canavial.

Na região de Campos, Neves (1997) observou que, inicialmente, os trabalhadores se negavam a cortar cana queimada, por causa dos malefícios que tal prática trazia à saúde, como maiores riscos de acidentes nos olhos, 
dificuldades respiratórias, piores condições de higiene e penosidade do trabalho. Os produtores de cana perceberam que a queima do canavial era o principal responsável pela diminuição da produtividade agrícola, pois tornava o solo menos fértil, além de ser um dos responsáveis pelas secas e irregularidades pluviométricas que vinham ocorrendo na região. Estes supunham que a presença da palhada da cana no solo poderia aumentar a fertilidade e a umidade do solo. Ademais, o corte da cana crua ampliaria a remuneração, porque o pagamento desta é pelo grau de sacarose e impureza. Entretanto, os plantadores de cana não estavam conseguindo obter a adesão dos trabalhadores para o corte da cana crua, e a prática da queima da cana se consolidou por volta da década de 1980.

Vale notar que o corte da cana crua aumenta os riscos de ataques de animais peçonhentos e os acúleos de sílica presentes nas folhas da cana arranham e cortam a pele. Outrossim, o podão, utilizado no corte da cana, enrosca-se na palhada, o que aumenta a penosidade e reduz a produtividade do trabalho. Por esses e outros motivos, os trabalhadores preferem cortar a cana queimada.

Outra polêmica ambiental desencadeada pela expansão canavieira na região diz respeito à perda da biodiversidade, advinda da introdução da monocultura da cana. A implantação da monocultura da cana-de-açúcar no Brasil, durante a existência do PROALCOOL, ocorreu basicamente em áreas antes destinadas à pecuária extensiva e às culturas agrícolas anuais, num processo que pouco pressionou o deslocamento destas em direção às novas fronteiras agrícolas. Porém Rodrigues e Ortiz (2006) alertam que o novo ímpeto de crescimento da produção pode provocar a ocupação de áreas naturais e áreas destinadas à produção de alimentos, forçando o deslocamento de parte da pecuária e das produções de grãos, com a consequente destruição de hábitats, perda da biodiversidade e depreciação da paisagem.

Em Itapuranga, a depreciação da vista panorâmica é um fato perceptível, pois a expansão canavieira no território está alterando consideravelmente a paisagem do meio rural. Diversas áreas, onde habitualmente encontrava-se vegetação do cerrado, estão cedendo lugar à monocultura canavieira em proporções inimagináveis. Pasqualeto e Zito (2000) alertam que a expansão dos canaviais em áreas de florestas e biomas como o cerrado pode destruir a vegetação natural e provocar desequilíbrios ecológicos. Essa expansão comumente vem precedida pelo desmatamento, que nem sempre respeita as vegetações ciliares e áreas de reservas legais. $\mathrm{O}$ isolamento das reservas pela falta de manutenção dos "corredores ecológicos" e o distanciamento das áreas vegetais dos recursos hídricos causam tanto a erosão gênica quanto a perda da biodiversidade. Nas áreas desmatadas, em função da retirada da vegetação original após a implantação da monocultura, ocorrem a redução da microbiota do solo, a redução da biodiversidade local, o estreitamento da base genética e a depreciação da paisagem.

Alguns autores contrastam os efeitos devastadores provocados pela introdução das monoculturas com a diversidade ambiental que supostamente existe na agricultura familiar. Dessa forma, a ciência atua como um instrumento de legitimação ideológica, ao vincular o desenvolvimento sustentável como um atributo inerente à agricultura familiar. Dentre os vários autores que trabalham com esse enfoque, podem-se mencionar, a título de exemplo, Muller (2001) e Sachs (2003). Os autores enfatizam atributos valorativos relacionados à biodiversidade ambiental como uma das características inerentes à agricultura familiar, imputando-lhe vantagens comparativas em relação ao modelo patronal e uma racionalidade econômica e socialmente justa desse segmento de agricultores, bem como uma capacidade adaptativa às novas pautas éticas atrelados à preservação ambiental. Mas, como ressalta Neves (2007), esses aspectos valorativos expressos em relação à agricultura familiar, como a ênfase na diversificação, na durabilidade dos recursos, na consciência ecológica, dentre outros, não podem ser generalizados a todas as unidades familiares. Tais argumentos visam apenas à construção de uma categoria socioprodutiva desejada, porém essa construção é sempre passível de novas reinterpretações.

Evidências dessas reinterpretações foram observadas no desenrolar das explanações do secretário do Meio Ambiente de Itapuranga, quando chama atenção para o fato de os pesquisadores questionarem a atuação 
de empreendimentos agroindustriais como sendo os "vilões" do meio ambiente. O secretário, particularmente, considera a agroindústria canavieira do município uma "parceira ambiental", uma vez que fez a doação de mudas de cerca de 3.500 para recuperação das nascentes e matas ciliares. Em contrapartida, ressalta que os agricultores familiares do município degradam mais o meio ambiente do que os empreendimentos agroindustriais.

Nota-se que esse representante do município de Itapuranga atua claramente na defesa dos interesses econômicos ligados à agroindústria canavieira, aceitando a inobservância dos aparatos legais e das práticas degradantes ao meio ambiente, quando sua função é justamente o contrário. Durante o levantamento de dados da pesquisa, observou-se o desmatamento de áreas de reservas legais e de matas pela agroindústria canavieira, em desrespeito à legislação pertinente. Sobre os inconvenientes da implantação da monocultura canavieira no município, o secretário do meio ambiente explica que não se trata da introdução de uma monocultura, mas apenas da substituição da monocultura de capim-braquiária - predominante na região - pela cana, procurando com isso amenizar os problemas relacionados à expansão da monocultura canavieira na região.

No atual programa agroenergético, o Estado estimula a produção de cana-de-açúcar pelos agricultores familiares, com a ressalva de que as políticas de incentivo à produção de biocombustíveis por estes agricultores devem atentar, sobretudo, para as questões relacionadas à preservação da biodiversidade existente nas unidades familiares. O Estado observa que a implantação de monoculturas nas propriedades familiares seria desastrosa para o meio ambiente e para a sustentabilidade dos agricultores, posto que suas principais características envolvem a capacidade de desenvolver várias atividades simultâneas, condição essa que, garante a biodiversidade dos agroecossistemas (MAPA et al., 2005). Essa prerrogativa do discurso estatal é contraditória, uma vez que quase todas as culturas agroenergéticas são monocultivos extensivos.

Ademais, observa-se uma dissonância entre os discursos do Estado nas diferentes esferas do poder público, pois, no plano regional, cogita-se a instituição do que se inti- tulou "Política de regularização do avanço da cana-de-açúcar", a fim de conter a expansão canavieira em áreas de agricultura familiar no contexto do território goiano. Até o momento, o projeto visa apenas chamar a atenção para possíveis impactos ambientais decorrentes do cultivo da cana e para as implicações do avanço da cana em áreas de agricultura familiar. Ressalte-se que ainda não foram implementadas ações concretas no sentido de conter os problemas anunciados, apenas propôs-se um debate sobre o tema (MDA; SDT; SAF, 2007).

A perda da biodiversidade natural também se deve aos efeitos perversos das queimadas. Segundo Gonçalves (2007), a queima da cana provoca uma verdadeira devastação, pois o fogo destrói ecossistemas, fauna, flora e microorganismos, afetando negativamente o equilíbrio agroecológico. Os animais da flora silvestre de áreas ambientais adjacentes correm risco de vida, uma vez que os predadores procuram suas presas à noite, justamente no período em que o fogo é ateado no canavial. O escape do fogo para áreas de vegetação ciliar e de preservação permanente também pode provocar a morte ou a redução das populações de espécies de vertebrados e insetos pela eliminação de seus hábitats.

Outro problema ambiental muito debatido em Itapuranga refere-se à derrubada das árvores que ocorre, principalmente, no período noturno. Durante o dia, os tratoristas da agroindústria preparam o solo nas propriedades arrendadas, mas deixam as árvores no local. Ao anoitecer, eles retornam para derrubá-las e enterrá-las logo em seguida para esconder a infração ambiental. Em meio às lavouras de cana-de-açúcar, as árvores são percebidas como empecilhos ao deslocamento das máquinas e às atividades relacionadas ao cultivo da cana. Mesmo que as deixassem na área, rapidamente seriam atingidas durante a queima do canavial.

A população fica indignada com a conivência dos fiscais e representantes políticos do município com a prática desse crime ambiental. Os entrevistados observam que os fiscais ambientais não tomam providências para inibir a destruição das árvores, preferindo fazer "vista grossa" e ignorar as infrações da lei. Eles também reclamam que os fiscais adotam tratamentos diferenciados para com a agroindústria e os agricultores familiares. 
Quando um agricultor familiar precisa retirar uma árvore para sanar necessidades da propriedade, os fiscais ambientais não permitem. Em contrapartida, a agroindústria pode derrubar várias árvores, até mesmo as protegidas por lei, que os fiscais nada fazem.

Essas ações contradizem as diretrizes instituídas pela política agroenergética, que defende a observância da política ambiental brasileira e dos dispositivos do Mecanismo de Desenvolvimento Limpo (MDL) do Protocolo de Quioto (MAPA et al., 2005b). Contrastam ainda com as recomendações de uma produção de culturas energéticas sustentadas em bases ambientalmente sustentáveis:

A agroenergia é um modelo de produção de energia que tem um expressivo potencial de promoção da sustentabilidade, sobretudo porque permite sistemas de produção de insumos energéticos em bases ambientalmente adequadas. (MAPA et al., 2005a, p. 25).

Vale notar que a derrubada das árvores é minimizada pelo secretário do Meio Ambiente de Itapuranga, quando este ressalta que não se trata de um crime ambiental a ponto de merecer tanta importância por parte da sociedade, uma vez que a agroindústria está mitigando o problema com a doação de mudas para o replantio. Esse mesmo agente social afirma que a população "estranha" o fato de a agroindústria derrubar madeiras protegidas por lei. Segundo ele, o que a população realmente precisa é aprender a conviver com a modernidade, ao invés de criar empecilhos ambientais para as atividades que trazem desenvolvimento para o município. Segundo seu ponto de vista, é inaceitável que a população critique algo "benéfico" para o município, por não desejarem o "progresso". No entanto, "estranho" é um representante do poder público local, que deveria coibir tais crimes ambientais, naturalizar a destruição ambiental e atos infração previstos no Artigo 45 da Legislação Ambiental Federal, n. 9.605, de 12 de fevereiro de 1998.

A agroindústria canavieira demonstra ter consciência das críticas decorrentes da corte das árvores e procura adotar medidas para atenuar o problema, com o plantio de árvores nas áreas e a não utilização das áreas legalmente protegidas. De fato, ao cercar, proteger e deixar inutilizada uma área de mata ciliar ou de preservação permanente pode haver a recomposição da vegetação natural. Porém, essa forma de reflorestamento - pouco dispendiosa - produz resultados muito demorados. Geralmente, na prática, isso não chega a ocorrer, pois, ao ceder suas terras à agroindústria, os agricultores permanecem utilizando a área baixa que corresponde a áreas de mata ciliar para os cultivos de subsistência, por considerá-las mais férteis e úmidas.

O cultivo da cana-de-açúcar também provoca a degradação do solo. Pasqualeto e Zito (2000) explicam que durante o cultivo da lavoura canavieira pode decorrer da compactação do solo, em função do uso de máquinas, veículos e equipamentos pesados durante o plantio, tratos culturais e colheita. Vale notar que a compactação do solo não só prejudica a penetração das raízes das plantas e, consequentemente, a absorção de nutrientes, como também diminui a mineralização da matéria orgânica. A compactação repercute ainda na queda das taxas de infiltração de água, pela diminuição de sua porosidade. Outro agravante é a pulverização do solo que, aliado a uma menor capacidade de infiltração de água, aumenta o escoamento superficial das águas pluviais, gerando enxurradas que promovem o assoreamento dos cursos d'água, a depreciação da qualidade do ar e da água, bem como a perda de áreas cultiváveis pela formação de erosões e de voçorocas.

No entanto, em decorrência da difícil percepção, os entrevistados não problematizaram a degradação do solo, apenas manifestaram descontentamento com o tráfego intenso nas estradas do município, que levanta poeira e agrava o estado de conservação das estradas. Apenas os representantes dos agricultores familiares demonstram preocupação com a degradação do solo e temem que, no futuro, esta venha a dificultar a retomada da atividade agrícola e até, em condições extremas, a inviabilizar a reprodução social destes agricultores, obrigando-os a vender suas propriedades.

Alguns autores concordam que a cultura canavieira apresenta vantagens em relação à preservação do solo, quando comparada a outras culturas. Isso decorre das próprias características da planta e pelo fato de o manejo sustentável do solo ser uma prática pouco empreendida pela maioria dos pequenos agricultores. Segundo Rodrigues e 
Ortiz (2006), quando a introdução da cultura canavieira ocorre conforme técnicas avançadas de manejo agrícola ela tende a reduzir a erosão do solo, o que não ocorre em manejos de pastos ou de produção de grãos. Além disso, a cultura de cana-de-açúcar protege mais o solo do que as pastagens e demais culturas anuais, porque apresenta intenso perfilhamento na sua fase inicial de crescimento e intenso crescimento do colmo principal, que propiciam cobertura vegetal mais homogênea e densa. Por ser uma gramínea de cultivo semiperene, seu sistema radicular oferece reposição contínua de material orgânico ao solo, reestruturando-o e ativando a porção viva do ambiente (microrganismos e microfauna), melhorando as condições de retenção de água e seu percolamento pelo perfil do solo. Entretanto, os autores observam que, apesar de atualmente haver maior conscientização em relação à conservação do solo, ainda há processos erosivos que desencadeiam a perda de suas camadas superficiais, com o consequente assoreamento dos rios.

Os impactos sobre os recursos hídricos somam-se aos problemas ambientais desencadeados pela cultura canavieira. O município de Itapuranga é recortado por vários cursos d'água que suprem de maneira eficaz a produção agrícola desenvolvida pelos agricultores familiares. Porém, alguns entrevistados manifestaram preocupações com o aumento da demanda hídrica da cultura agroenergética, que pode comprometer a disponibilidade de água, tanto para a produção agropecuária quanto para o consumo da população. Como observam Rodrigues e Ortiz (2006), a preservação dos recursos hídricos merece atenção em todas as etapas do processo produtivo, uma vez que o cultivo de cana-de-açúcar em grande escala e a produção industrial de etanol demandam uma grande quantidade de água, proveniente da captação superficial, o que leva à indução de processos erosivos, com consequente assoreamento dos corpos d'água superficiais.

Os inconvenientes decorrentes da aplicação do vinhoto - um subproduto resultante do processamento da cana - na fertirrigação da cultura da cana-de-açúcar também pode causar impactos perversos sobre os recursos hídricos. Andrade (1994) esclarece que esse subproduto merece muita atenção, em decorrência da grande quantidade que é gerado, uma vez que o seu volume equivale a treze vezes o volume do álcool produzido. De acordo com Dias (2006), a carga de matéria orgânica no vinhoto é alta, sendo necessária a retirada de muito oxigênio da própria água para sua decomposição. O alto índice de demanda bioquímica de oxigênio (DBO), necessária à decomposição aeróbica, e de demanda química de oxigênio (DQO) do vinhoto e vinhaça causam sérios problemas ao sistema aquático. Além do mais, o vinhoto a $107^{\circ} \mathrm{C}$ é ácido e corrosivo, se lançado diretamente na natureza. Entretanto, o vinhoto pode ser usado como biofertilizante. Para isso precisa ser armazenado em condições específicas, para não ocorrer vazamentos. Outrossim, apresenta como inconveniente a possibilidade de salinização do solo.

Segundo Magalhães, Kuperman e Machado (1991), o vinhoto pode provocar desastres ambientais, principalmente, se for lançado nos rios sem qualquer tratamento e/ ou quando utilizado em excesso como biofertilizante na fertirrigação. Em tais situações, pode causar a salinização do solo e a poluição dos recursos hídricos, pois as chuvas podem levá-lo para os cursos d'águas. O armazenamento do vinhoto em lagoas de despejo ou de decantação dispensa seu lançamento em cursos d'água, mas apresenta como inconveniente a possibilidade de contaminação do lençol freático. Os autores expõem três fatores que, na prática, impedem que o vinhoto polua o meio ambiente: 1) a existência de tecnologia que reduz a relação álcool-vinhoto produzido; 2) o armazenamento em condições que dispensem seu lançamento em cursos d'água; 3) a utilização do vinhoto na produção de gás, ração animal, fertilizantes etc. A fertirrigação é o uso mais comum, mas, em áreas mais acidentadas, os custos de transporte se elevam, tornando essa prática inviável.

A partir de 1980, tornaram-se uma exigência o beneficiamento e o aproveitamento desse subproduto junto aos projetos de implantação de destilarias. Porém, na prática, tal exigência nem sempre é adotada. Uma pesquisa realizada pela COPERSUCAR (1989) revelou que 63\% do vinhoto gerado nas destilarias associadas à cooperativa foram utilizados nas lavouras como fertilizante e $37 \%$ foram desviados para lagoas de despejo. Apesar da possibilidade de utilização 
desse subproduto, Andrade (1994), Adissi e Spagnul (2000) chamaram a atenção para a ocorrência de algumas descargas ilegais de vinhoto nos rios, provocando sérios problemas de abastecimento de água das cidades e das próprias indústrias, bem como a contaminação do lençol freático das áreas agrícolas. Outro problema comum referese à localização das lagoas de decantação, que incomodam as populações vizinhas, em virtude do forte odor que exalam.

Durante o PROACOOL eram frequentes as denúncias de poluição de rios por vinhoto nas regiões canavieiras de Goiás. Santos (1987) afirma que, na década de 1980, as principais irregularidades provocadas pelas agroindústrias canavieiras goianas referiamse à liberação do vinhoto em mananciais e ao modo inadequado de aplicação do vinhoto na fertirrigação. A aspersão por caminhõestanque com queda livre era o método de aplicação mais utilizado pelas destilarias, apresentando como inconveniente a possibilidade de vazamento de vinhoto pela vertente, impondo riscos aos mananciais d'água.

Conforme demonstrativo apresentado pela antiga Secretaria do Meio Ambiente de Goiás (Semago), em 1983 foram lavradas advertências e multas à Destilaria Pite S.A., localizada em Itapuranga. A agroindústria em questão foi responsável por um dos maiores desastres ambientais já registrados no estado. Conforme o Relatório 139/82, de 5 de outubro de 1982 da SEMAGO, foram lançados, aproximadamente, 13 milhões de litros de vinhoto nas águas do ribeirão Canastra, ameaçando os municípios de Itapuranga, Uruana, Ceres e Rialma, o que gerou grande mortandade de peixes, colocando também em risco o abastecimento de água à população (SANTOS, 1987).

Atualmente, a agroindústria canavieira de Itapuranga utiliza o vinhoto na fertirrigação das áreas de cultivo da cana-de-açúcar. As experiências da população local relacionada a essa prática sempre estiveram associadas aos inconvenientes do odor, embora ainda esteja presente na memória coletiva o desastre ecológico causado pela agroindústria canavieira instalada anteriormente. Assim, os entrevistados que residem nas proximidades da agroindústria temem serem sujeitos a reviver as experiências negativas decorrentes da utilização do vinhoto.

Em suma, as opiniões dos agricultores familiares e demais agentes sociais de Itapuranga divergem em relação aos desdobramentos ambientais relacionados ao desenvolvimento da atividade canavieira no município. Contudo, de maneira geral, são frequentes as denúncias de crimes ambientais praticados pelas agroindústrias canavieiras no estado de Goiás como um todo. O Ministério Público de Goiás (MP-GO) está apurando várias denúncias de crimes ambientais praticados pelas agroindústrias no Estado. Em Acreúna, GO, o $\mathrm{MP}$ notificou que durante a queima da cana o fogo avança sobre áreas de pastagens e de preservação permanente. Outras falhas remetem à falta de preparo das agroindústrias para o combate a incêndios, ao descarte irregular de resíduos oriundos do processamento da cana, bem como de embalagens de agrotóxicos, e à precariedade dos equipamentos de proteção individual dos trabalhadores (MP-GO 2008).

\section{Conclusão}

A introdução da cana em Itapuranga, apesar de ser um processo recente, foi suficiente para provocar alterações consideráveis nas relações da sociedade com a natureza. A emergência de contradições ambientais fornece subsídios para ser questionada a viabilidade da nova "política agroenergética como impulsionado do desenvolvimento sustentável no interior do país", conforme discursos oficiais propalados no Plano Nacional de Agroenergia. Nesse contexto, a noção de desenvolvimento sustentável é utilizada como uma ideologia, no intuito de transparecer as vantagens ambientais, obscurecer as contradições socioambientais e atenuar os conflitos desencadeados ao longo do processo produtivo.

A nova conformação do espaço social, decorrente da implantação da agroindústria em Itapuranga, vem alterando as relações da sociedade como o meio ambiente, uma vez que promove transformações significativas na paisagem, suscitando uma maior disputa pelos recursos naturais que se expressam em segregações de grupos e disputas de poder. As opiniões dos agricultores familiares e demais agentes sociais divergem em relação às questões ambientais associadas à produção de cana no município. Alguns agentes tendem a enfatizar os problemas ambientais e outros procuram destacar os supostos benefícios 
advindos ao meio ambiente. As opiniões estão muitas vezes condicionadas ao posicionamento dos agentes no espaço social analisado, que os levava a auferir benefícios ou não com a nova conformação traçada pelo circuito produtivo da cana.

Por isso os impasses ambientais são percebidos pelos diversos grupos e agentes sociais de Itapuranga sob diferentes perspectivas. Alguns grupos e agentes sociais tecem críticas às políticas de estímulo à expansão canavieira, destacando as diversas formas de degradação ambiental associadas ao cultivo da cana, como os malefícios das queimadas, os impactos adversos das monoculturas sobre o meio ambiente, a perda da biodiversidade natural e a degradação e poluição dos ecossistemas. A degradação ambiental é problematizada, sobretudo, pelos grupos de representação dos agricultores familiares, por agentes sociais e agricultores familiares contrários à implantação do empreendimento canavieiro no município. Outros tendem a enfocar os aspectos positivos relacionados à produção e utilização dos biocombustíveis oriundos da cana-de-açúcar, como o sequestro de gás carbônico e redução das emissões de poluentes atmosféricos, associando-os ao desenvolvimento sustentável. Os representantes autorizados pelo poder municipal, na expectativa de aumentar a arrecadação de impostos provenientes das atividades da agroindústria canavieira, atenuam os problemas e os crimes ambientais cometidos pelo empreendimento e ressaltam os benefícios ambientais relacionados a ele, como a doação de mudas para reflorestamento. Em suma, consideram que as vantagens econômicas e sociais superam e compensam as perdas e danos ambientais, como se fosse um preço justo a se pagar pelo desenvolvimento e progresso do município.

\section{Referências}

ADISSI, P. J.; SPAGNUL, W. A atividade canavieira nordestina e a certificação socioambiental. In: FERRAZ, J. M. G.; PRADA, L. de S.; PAIXÃO, M. (Org.). Certificação socioambiental do setor sucroalcooleiro. São Paulo: Embrapa Meio Ambiente, 2000.

ANDRADE, M. C. de. Modernização e pobreza: a expansão da agroindústria canavieira e seu impacto ecológico e social. São Paulo: UNESP, 1994.

BIERHALS, J. D. A colheita mecanizada é o futuro da canade-açúcar: leis ambientais e carência de mão-de-obra tendem a pôr fim no corte manual. Disponível em: <http://www.infp.org.br>. Acesso em: 25 jul. 2007.

BORGES, U.; FREITAG, H.; HURTIENNE, T.; NITSCH, M. PROALCOOL: economia política e avaliação sócio-econômica do programa brasileiro de biocombustível. Aracaju: UFS, 1988.

BOURDIEU, P. Coisas ditas. São Paulo: Brasiliense, 1990. . Razões práticas: sobre a teoria da ação. Campinas, SP: Papirus, 1996.

. A miséria do mundo. Petrópolis, RJ: Vozes, 1997.

. A economia das trocas lingüísticas: o que fala quer dizer. São Paulo: EDUSP, 1998a.

. Contrafogos: táticas para enfrentar a invasão neo-liberal. Rio de Janeiro: Jorge Zahar, 1998b.

Brasil, 1998c.

O poder simbólico. Rio de Janeiro: Bertrand

BRASIL. Lei Federal n. 9.605 de 12 de fevereiro de 1998. Dispõe sobre as sanções penais e administrativas derivadas de condutas e atividades lesivas ao meio ambiente, e dá outras providências. Disponível em: <http:/ / www. mma.gov.br>. Acesso em: 11 out. 2007.

. Plano Nacional de Agroenergia Revisado 2006-2011. 2. ed. rev. Brasília: Embrapa Informação Tecnológica, 2006. Disponível em: <http://www.embrapa.br>. Acesso em: 22 abr. 2007.

COPERSUCAR. Proálcool: fundamentos e perspectivas. São Paulo: Copersucar, 1989.

DIAS, F. A questão da água: poluição e uso abusivo In: SEMINÁRIO CIENTIFICO BRASILEIRO SOBRE AS PROBLEMÁTICAS SOCIAIS E AMBIENTAIS DO SETOR CANAVIEIRO, 2., 2006. Anais... São Paulo: Açúcar Ético, 2006. Disponível em: <http:/ / www.sucre-ethique.org>. Acesso em: 25 ago. 2007.

FERRAZ, J. M. G. Setor sucroalcooleiro, agribusiness e ambiente. In: FERRAZ, J. M. G.; PRADA, L. de S.; PAIXÃO, M. (Orgs.). Certificação socioambiental do setor sucroalcooleiro. São Paulo: Embrapa Meio Ambiente, 2000.

GOIÁS. Lei Estadual n. 15.834, de 23 de novembro de 2006. Dispõe sobre redução gradativa da queima da palha de cana-de-açúcar em áreas mecanizáveis e dá outras providências. Disponível em: <http:/ / www.gabinetecivil. goias.gov.br>. Acesso em: 4 nov. 2008.

GONÇALVES, D. B. Meio ambiente e cana-de-açúcar: impactos e perspectivas. In: SEMINÁRIO CIENTÍFICO BRASILEIRO SOBRE AS PROBLEMÁTICAS SOCIAIS E AMBIENTAIS DO SETOR CANAVIEIRO, 2. Disponível em: <http://www.sucre-ethique.org>. Acesso em: 25 ago. 2007.

INSTITUTO Brasileiro de Geografia e Estatística (IBGE_. Pesquisa agrícola municipal. 2006. Disponível em: <http:/ / www.sidra.ibge.gov.br>. Acesso em: 10 jun. 2007.

MAGALHÃES, J. P. de A.; KUPERMAN, N.; MACHADO, R. C. Proalcool: uma avaliação global. Rio de Janeiro: Astel, 1991.

MAPA; MCT; MME; MDI\&CE. Diretrizes de politica de agroenergia 2006-2011. Brasília, DF: MAPA, 2005a. Disponível em: <http://www.mapa.gov.br>. Acesso em: 22 abr. 2007. 
. Plano Nacional de Agroenergia 2006-2011. Brasília, DF: Embrapa Informação Tecnológica, 2005b. Disponível em: <http://www.embrapa.br>. Acesso em: 22 abr. 2007.

MINISTÉRIO DO DESENVOLVIMENTO AGRÁRIO (MDA), SECRETARIA DE DESENVOLVIMENTO TERRITORIAL (SDT), COORDENAÇÃO GERAL DE NEGÓCIOS E COMÉRCIOS (CGNC) E SECRETARIA DE AGRICULTURA FAMILIAR (SAF). Plano Safra Territorial Vale do Rio Vermelho Goiás (PST). Brasília, 2007.

MINISTÉRIO PÚBLICO DO ESTADO DE GOIÁS. Perito ambiental do MP vistoria área incendiada em Acreúna. Notícia, 26 set. 2008. Disponível em: <http://www.mp.go.gov.br/portalweb/conteudo. jsp? page $=9 \&$ conteudo $=$ noticia. html $>$. Acesso em: 28 out. 2008.

MULLER, J. M. Transição, sustentabilidade e agricultura familiar. Perspectiva, Erexim, v. 5, n. 92, p. 53-66, dez. 2001.

NEVES, D. P. Agricultura familiar: quantos ancoradouros! Disponível em: <http:/ / www.prudente.unesp.br>. Acesso em: 8 out. 2007.
. Os fornecedores de cana e o estado intervencionista: estudo do processo de constituição social dos fornecedores de cana. Niterói: EDUFF, 1997.

PASQUALETO, A.; ZITO, R. K. Impactos ambientais da monocultura da cana-de-açúcar. Goiânia: Ed. UFG, 2000.

RODRIGUES, D.; ORTIZ, L. Em direção à sustentabilidade da produção de etanol de cana-de-açúcar no Brasil. 2006. Disponível em: <http://vitaecivilis.org.br>. Acesso em: 20 ago. 2007.

SACHS, I. Inclusão social pelo trabalho: desenvolvimento humano, trabalho decente e o futuro dos empreendimentos de pequeno porte. Rio de Janeiro: Garamond, 2003.

SANTOS, M. H. M. e C. A expansão canavieira em Goiás e seus reflexos: exemplo de Santa Helena de Goiás. 1987. Dissertação (Mestrado) - Universidade de São Paulo, São Paulo, 1987.

SEPLAN/SEPIN. Goiás em dados 2007. Disponível em: <http://www.seplan.go.gov.br/sepin/>. Acesso em: 15 nov. 2008.

Perfil socioeconômico de Itapuranga. Disponível em: <http://portalsepin.seplan.go.gov.br/>. Acesso em: 22 set. 2007. 
